\title{
DOENÇAS FÚNGICAS DA CULTURA DA ERVA-MATE (Ilex paraguariensis) NO BRASIL
}

\section{FUNGAL DISEASES OF YERBA-MATE CULTURE (Ilex paraguariensis) IN BRAZIL}

\author{
Roberto de Resende Lisboa Piassetta1 ${ }^{1}$, Ana Paula Mikos², Celso Garcia Auer ${ }^{3}$ \\ 1,2 Universidade Federal do Paraná, Curitiba, Paraná, Brasil-robertopiassetta@gmail.com \& \\ anapaulamikos@hotmail.com \\ ${ }^{3}$ Embrapa Florestas, Colombo, Paraná, Brasil - celso.auer@embrapa.com
}

\begin{abstract}
RESUMO
A erva-mate (Ilex paraguariensis) é uma espécie florestal de ocorrência natural na região Sul do Brasil, e se destaca pela forte cultura de consumo como chá e chimarrão. O Brasil, mesmo sendo o país com maior área de ervais nativos, é o segundo maior produtor da planta do mundo. Com o aumento do consumo da erva-mate, ocorreu a substituição de ervais nativos por ervais plantados, o que causou maior susceptibilidade às pragas e doenças. O objetivo do presente artigo foi realizar uma revisão sistemática para identificar quais as principais doenças fúngicas que ocorrem na cultura. A busca dos artigos foi realizada nas bases de dados Google Scholar, Periódicos CAPES e Scielo. As palavras-chave utilizadas foram "doenças erva-mate", "fungos erva-mate" e "Fusarium erva-mate". No total, foram avaliados 16 artigos, sendo que 7 abordaram a ocorrência de fungos associados a erva-mate, 6 artigos específicos de fungos patogênicos em erva-mate e 3 abordaram métodos de controle de doença em erva-mate. Os artigos também foram classificados em ano de publicação, local de coleta, objetivo do estudo, doença encontrada/avaliada, tipo de amostra e tipo de experimento realizado. O fungo mais frequente foi Fusarium (podridão-de-raízes), que atinge a cultura da erva-mate na região Sul do Brasil. Além disso, também foram abordadas as doenças causadas pelo patógeno Cylindrocladium spathulatum (pinta preta), em artigos mais antigos e Ceratocystis fimbriata (murcha vascular) em um artigo mais recente.
\end{abstract}

Palavras-chaves: Floresta, Fungo, Fusarium.

\begin{abstract}
Yerba mate (Ilex paraguariensis) is a forest species that occurs naturally in the southern region of Brazil, and stands out for its strong culture of consumption as tea and mate. Brazil, even though it is the country with the largest area of native yerba mate, is the second largest producer of the plant in the world. With the increase in the consumption of yerba mate, there has been a substitution of native yerba-mate by planted ones, which has caused greater susceptibility to pests and diseases. The paper aims to carry out a systematic review to identify which are the main fungal diseases that occur in the crop. The search for articles was conducted in Google Scholar, CAPES Periodicals and Scielo databases. The keywords used were "yerba-mate diseases", "yerba-mate fungi" and "Fusarium yerba-mate". In total, 16 articles were evaluated, of which 7 addressed the occurrence of fungi associated with yerba mate, 6 articles specific to pathogenic fungi in yerba mate, and 3 addressed methods of disease control in yerba mate. The articles were also classified by year of publication, place of collection, objective of the study, disease found/evaluated, type of sample and type of experiment carried out. The most frequent fungus was Fusarium (root rot), that affects the yerba mate culture in Southern region of Brazil. In addition, the diseases caused by the pathogen Cylindrocladium spathulatum (black spot), in older articles, and Ceratocystis fimbriata (vascular wilt) in a more recent article were also presented.
\end{abstract}

Keywords: Forest, Fungus, Fusarium. 


\section{INTRODUÇÃO}

A erva-mate, Ilex paraguariensis St. Hil, é uma planta originária do Brasil e do Paraguai, e possui folhas e ramos que são consumidos muitas vezes em sua forma natural, como o chimarrão, chás e tererê, além de ser a fonte de vários produtos utilizados na indústria alimentícia, química e farmacêutica. É utilizada desde os povos nativos, passando para os europeus que colonizaram o Brasil, a partir do século XVI. Também pode ser denominada chá-de-Paraguai, chá dos jesuítas, erva do diabo, yerba-santa (DANIEL, 2009).

No Brasil, estima-se que atualmente existem mais de $700 \mathrm{mil}$ ha destinados ao cultivo da erva-mate, distribuídos em aproximadamente 480 municípios e com 180 mil propriedades. Grande parte da área cultivada se concentra na região Sul do país (MEDRADO \& VILCAHUAMAN, 2014). No ano de 2019, foram colhidos aproximadamente $67 \mathrm{mil}$ ha de ervais, totalizando 517.779 toneladas de erva-mate (IBGE, 2021). Os estados com maior participação foram Rio Grande do Sul, Paraná, Santa Catarina e Mato Grosso do Sul, com 45,1\%, 37,2\%, $17,4 \%$ e $0,3 \%$ da produção, respectivamente. O valor da produção atingiu aproximadamente 477 milhões de reais (IBGE, 2021).

Diversas doenças foram relatadas em erva-mate. Gomes et al. (2001) e Grigoletti Junior \& Auer (2003) indicaram que doenças como a pinta-preta, causada pelo Cylindrocladium spathulatum, podem provocar grandes prejuízos e inviabilizar seu cultivo. Com o aumento da área plantada, principalmente na última década, a ocorrência de pragas e doenças aumentou, e a podridãode-raízes também se tornou um dos principais problemas fitossanitários encontrados na cultura da erva-mate. Além disso, também são destacados problemas relacionados ao manejo da espécie como a adubação incorreta, plantio em épocas inadequadas, mudas de baixa qualidade e áreas susceptíveis a doenças (POLETTO et al. 2010).

O solo de cultivo é um habitat propício para o desenvolvimento de fungos patogênicos para a cultura de erva-mate (BORGES et al., 2011). Em alguns casos, o método de obtenção e estratificação de sementes utilizado nos viveiros também pode contribuir para o aumento da ocorrência de doenças no viveiro. Além disso, as plantas podem estar contaminadas e não apresentarem sintomas, e com isso podem contaminar áreas livres de patógenos (POLETTO et al., 2015).

O objetivo do trabalho foi realizar uma revisão sistemática visando determinar os principais gêneros fúngicos causadores de doenças a cultura de erva-mate.

\section{MATERIAL E MÉTODOS}

Para a elaboração deste trabalho, foi realizada uma revisão sistemática da literatura nas bases de dados Google Scholar, Periódicos CAPES e Scielo. As palavraschave utilizadas foram "doenças erva-mate", "fungos erva-mate" e "Fusarium erva-mate". Foram utilizados somente artigos publicados após 2000, que abordavam doenças fúngicas em erva-mate e com estudos realizados no Brasil.

Os artigos encontrados foram classificados de acordo com o ano de publicação, local de coleta, objetivo do estudo, doença encontrada/avaliada, tipo de amostra e tipo de experimento realizado.

\section{RESULTADOS E DISCUSSÃO}

Em todas as bases de dados avaliadas, foram encontrados 36 artigos no total. Após a leitura e triagem, foi observado que alguns artigos se repetiam ou não se encaixavam nos critérios do estudo. Para a avaliação final, foram selecionados 16 artigos para sua análise.

$\mathrm{O}$ ano mais frequente de publicação dos artigos foi 2018 com 3 artigos, e frequência de 2 artigos nos anos de 2006, 2010 e 2015.

Os estudos foram realizados nos estados da região Sul do Brasil, com maioria deles no estado do Rio Grande do Sul, totalizando 10 artigos. Os demais artigos foram desenvolvidos no estado do Paraná (4 artigos) e em Santa Catarina (1 artigo), e um dos artigos utilizou amostras de erva-mate de Santa Catarina e do Rio Grande do Sul.

Os artigos encontrados também foram classificados de acordo com o objetivo da pesquisa. Dentre eles, 3 artigos abordam os métodos de controle para fungos comuns em erva-mate; 7 artigos são gerais sobre identificação de doenças na cultura e 6 artigos específicos para Fusarium ou Ceratocystis.

O gênero Fusarium foi o fungo mais estudado, sendo abordado em 13 artigos dos 16 artigos avaliados, e em 6 foram contempladas a doença podridão-de-raízes causada por este fungo. A exceção foram os artigos publicados por Gomes et al. (2001) e Grigoletti Junior \& Auer (2003) que relataram a doença pinta-preta, causada pelo fungo C. spathulatum, e Brito et al. (2021), que estudaram apenas o fungo Ceratocystis fimbriata na ervamate.

Na sequência, serão discutidos os artigos de acordo com a divisão realizada referente ao objetivo: métodos de controle, identificação de doenças e artigos específicos. 


\section{Ocorrência de fungos associados com a erva-mate}

Dentre os artigos analisados, 7 abordaram a identificação de ocorrência de fungos em erva-mate. A Tabela 1 apresenta um resumo dos artigos avaliados, com o autor, amostra coletada e os patógenos identificados.

Tabela 1. Artigos sobre a identificação de fungos em ervamate.

\begin{tabular}{|c|c|c|}
\hline Autor & Amostra & Gêneros \\
\hline $\begin{array}{l}\text { Pimentel et } \\
\text { al. (2006) }\end{array}$ & Folhas & $\begin{array}{l}\text { Acremonium sp. Fusarium sp., } \\
\text { Aspergillus sp., Penicillium sp., } \\
\text { Colletotrichum sp., Rhizoctonia sp., } \\
\text { Scopulariopsis sp., Trichoderma sp., }\end{array}$ \\
\hline $\begin{array}{l}\text { Poletto et } \\
\text { al. (2007) }\end{array}$ & Raízes & $\begin{array}{l}\text { Fusarium sp., Pythium sp. e } \\
\text { Rhizoctonia sp. }\end{array}$ \\
\hline $\begin{array}{l}\text { Borges et } \\
\text { al. (2011) }\end{array}$ & Solo & $\begin{array}{l}\text { Aspergillus sp., Penicillium sp., } \\
\text { Acremonium sp., Cladosporium sp., } \\
\text { Fusarium sp., Paecilomyces sp., } \\
\text { Rhizopus sp., Trichoderma sp., } \\
\text { Metarhizium sp., Gliocladium sp.e } \\
\text { Lecanicillium sp. }\end{array}$ \\
\hline $\begin{array}{l}\text { Oliveira et } \\
\text { al. (2015) }\end{array}$ & $\begin{array}{l}\text { Semente e } \\
\text { frutos }\end{array}$ & $\begin{array}{l}\text { Alternaria sp., Penicillium sp., } \\
\text { Rhizoctonia sp., Fusarium sp., } \\
\text { Phomopis sp., Trichoderma sp. }\end{array}$ \\
\hline $\begin{array}{l}\text { Poletto et } \\
\text { al. (2015) }\end{array}$ & $\begin{array}{l}\text { Flores, frutos, } \\
\text { sementes, } \\
\text { plântulas, } \\
\text { mudas e } \\
\text { substrato }\end{array}$ & $\begin{array}{c}\text { Fusarium spp., Rhizoctonia sp. } e \\
\text { Pythium sp. }\end{array}$ \\
\hline $\begin{array}{l}\text { Paula et al. } \\
\text { (2017) }\end{array}$ & Solo & $\begin{array}{l}\text { Fusarium sp., Aspergillus sp., } \\
\text { Penicillium sp., Cladosporium sp., } \\
\text { Verticillium sp., Botrytis sp., } \\
\text { Phomopsis sp. e Rhizopus sp., e } \\
\text { Trichoderma sp., }\end{array}$ \\
\hline $\begin{array}{l}\text { Paula et al. } \\
\text { (2018) }\end{array}$ & $\begin{array}{l}\text { Solo, mudas, } \\
\text { raízes, ramos e } \\
\text { frutos }\end{array}$ & $\begin{array}{l}\text { Fusarium sp., Colletotrichum sp., } \\
\text { Cylindrocladium sp., Rhizopus sp., } \\
\text { Cladosporium sp., Trichoderma sp. }\end{array}$ \\
\hline
\end{tabular}

Pimentel et al. (2006) avaliaram fungos endofíticos presentes em folhas de erva-mate no município de Colombo, Paraná. Foram comparadas folhas de ervais nativos e plantados, e de plantas jovens e adultas. Os gêneros encontrados, de maior para menor frequência foram: Penicillium sp., Aspergillus sp., Acremonium sp., Fusarium sp., Colletotrichum sp., Trichoderma sp., Rhizoctonia sp. e Scopulariopsis sp. Segundo os autores, nas folhas adultas e nativas ocorre maior diversidade de fungos endofíticos, quando comparado a folhas jovens e ervais plantados. No entanto, os fungos presentes nas folhas de ervais nativos apresentaram maior potencial de biocontrole, que podem contribuir para a proteção contra pragas e doenças.
Poletto et al. (2007) avaliaram fungos presentes em amostras de raízes de erva-mate com sintomas da doença podridão-das-raízes. As amostras foram coletadas nos municípios de Ilópolis e Putinga, do Vale do Taquari, no Rio Grande do Sul. Além do gênero Fusarium, também foram identificados os gêneros Pythium sp. e Rhizoctonia sp., como primeiro relato em ervais do Rio Grande do Sul. Também foram realizados testes de patogenicidade, em que os fungos mostraram potencial em causar a podridãode-raízes em plantas de erva-mate.

Borges et al. (2011) identificaram 11 diferentes gêneros de fungos filamentosos em amostras de solo de ervais do município de Campo Alegre, Santa Catarina, sendo: Aspergillus sp., Penicillium sp., Acremonium sp., Cladosporium sp., Fusarium sp., Paecilomyces sp., Rhizopus sp., Trichoderma sp., Metarhizium sp., Gliocladium sp.e Lecanicillium sp. Entre eles os mais encontrados ao longo de todas as estações do ano, foram Aspergillus sp., Penicillium sp., enquanto o Fusarium sp. foi identificado apenas nas estações de verão e outono. Os mesmos autores, ainda destacaram que alguns gêneros identificados podem ser empregados no controle de pragas e doenças da erva-mate.

Oliveira et al. (2015) avaliaram sementes e frutos coletados nos municípios de Anta Gorda, Rio Grande do Sul, e Ponte Serrada, Santa Catarina. Os autores utilizaram o método BDA e papel-filtro, indicando que foram eficientes para identificação dos fungos. Dentre 6 fungos identificados, o principal foi o Penicillium sp., constatado por ambos os métodos. O fungo Fusarium foi identificado em frutos e sementes, em apenas um dos lotes.

Poletto et al. (2015) estudaram a podridão-de-raízes em erva-mate em viveiro e em ervais dos municípios do Vale do Taquari, Rio Grande do Sul: Anta Gorda, Arvorezinha, llópolis e Putinga foram identificados os gêneros Fusarium spp., Rhizoctonia sp. e Pythium sp. Segundo estes autores, a podridão-de-raízes é a principal doença da cultura acarretando em sérios prejuízos em viveiro e a campo. Para os ensaios laboratoriais, foram coletados flores, frutos, sementes, plântulas, mudas e substrato. Os resultados dos ensaios indicaram que Fusarium spp. e Rhizoctonia sp. foram os principais patógenos contaminantes das sementes de erva-mate e que o método de obtenção das sementes e estratificação utilizado pelos viveiristas proporciona um aumento significativo da contaminação por patógenos, atingindo $100 \%$ das sementes no momento da semeadura. Além disso, a contaminação das flores, que atingiu $80 \%$ das amostras contaminadas por Fusarium sp., e do substrato pode ser uma porta de entrada de fungos. 
Paula et al. (2017) avaliaram a incidência de fungos em amostras de solo de ervais localizados no Alto Uruguai Gaúcho, nos municípios de Severiano de Almeida, Viadutos, Barão de Cotegipe, Ponte preta, Campinas do Sul e Erechim, estado do Rio Grande do Sul. O principal gênero identificado foi Fusarium sp., além de Aspergillus sp., Penicillium sp., Cladosporium sp., Verticillium sp., Botrytis sp., Phomopsis sp. e Rhizopus sp. Apesar de vários fungos terem sido encontrados no solo dos ervais, muitos deles não causam prejuízos para a cultura. Dentre eles está o gênero Trichoderma sp. presente nas amostras em porcentagens elevadas, com potencial de biocontrole frente as espécies do gênero Fusarium patogênicas a erva-mate. Borges et al. (2011) obtiveram resultados semelhantes, já que, também constataram a presença de Aspergillus e Penicillium, no entanto o Fusarium spp. foi encontrado com menor frequência no solo dos ervais de Santa Catarina.

As coletas de Paula et al. (2018) também foram realizadas nos municípios do Alto Uruguai, onde amostras de erva-mate como solo, mudas, raízes, ramos e frutos foram analisadas. Os autores identificaram o gênero Fusarium como predominante nas amostras de solo dos viveiros e ervais, comparado aos demais fungos. Além disso, 83,3\% dos ervais apresentam alta incidência de antracnose e pinta-preta na parte aérea das plantas.

\section{Artigos específicos de fungos em erva-mate}

Seis artigos analisaram avaliaram fungos específicos, como Fusarium e C. fimbriata. A Tabela 2 apresenta um resumo dos artigos avaliados, com o autor, município e o patógeno avaliado.

Poletto et al. (2006) identificaram as espécies de Fusarium spp. (Tabela 2) causadores de podridão-deraízes em ervais da região do Vale do Taquarí, nos municípios de Anta Gorda, Arvorezinha, Ilópolis e Putinga, no Rio Grande do Sul. As espécies identificadas foram $F$. oxysporum, F. solani, F. decemcellulare, F. tabacinum e $F$. tricinctum. Todas as espécies foram patogênicas quando inoculadas em plantas de erva-mate. F. oxysporum e $F$. solani foram os fungos mais comuns. As hipóteses apresentadas pelos autores foram: a contaminação derivada de outras culturas anuais como feijão e soja, mudas contaminadas do viveiro ou que o fungo seja um habitante natural do solo da região que se adaptou para atacar as plantas de erva-mate.

Poletto et al. (2010b) realizaram um experimento em esquema fatorial composto por inoculação de Fusarium spp. e em diferentes níveis de sombreamento. O objetivo da pesquisa foi avaliar o cultivo a pleno sol, que pode ser um fator estressante para a erva-mate tornando-a mais suscetível à podridão-de-raízes. As mudas utilizadas no experimento foram produzidas de sementes e adquiridas de um viveiro de Anta Gorda, RS, sem sintomas aparentes de doenças. Os isolados de F. oxysporum e F. solani foram inoculados juntos nos vasos das mudas e o nível de sombreamento variou de $0 \%, 26 \%, 41 \%, 84 \%$ e $95 \%$. Os autores concluíram que o melhor crescimento, desenvolvimento e maior resistência da erva-mate ocorreram com os maiores níveis de sombreamento.

Tabela 2. Artigos sobre a identificação de fungos em ervamate.

\begin{tabular}{|c|c|c|}
\hline Autor & Município & Patógeno \\
\hline $\begin{array}{l}\text { Poletto et } \\
\text { al. (2006) }\end{array}$ & $\begin{array}{c}\text { Anta Gorda, } \\
\text { Arvorezinha, llópolis e } \\
\text { Putinga, RS }\end{array}$ & $\begin{array}{c}\text { F. oxysporum, F. solani, } \\
\text { F. decemcellulare, } F \text {. } \\
\text { tabacinum } \\
\text { e F. tricinctum. }\end{array}$ \\
\hline $\begin{array}{l}\text { Poletto et } \\
\text { al. (2010b) }\end{array}$ & Anta Gorda, RS & F. oxysporum e F. solani \\
\hline $\begin{array}{l}\text { Poletto et } \\
\text { al. (2012) }\end{array}$ & $\begin{array}{c}\text { Anta Gorda, } \\
\text { Arvorezinha, llópolis e } \\
\text { Putinga }\end{array}$ & F. oxysporum e F. solani \\
\hline $\begin{array}{l}\text { Mezzomo } \\
\text { et al. } \\
(2018 a)\end{array}$ & Santa Maria, RS & F. oxysporum e F. solani \\
\hline $\begin{array}{l}\text { Mezzomo } \\
\text { et al. } \\
\text { (2018b) }\end{array}$ & $\begin{array}{c}\text { Anta Gorda, } \\
\text { Arvorezinha, Putinga, } \\
\text { Ilópolis e Machadinho, } \\
\text { RS }\end{array}$ & F. oxysporum e F. solani \\
\hline $\begin{array}{l}\text { Brito et al. } \\
\text { (2021) }\end{array}$ & $\begin{array}{c}\text { São Mateus do Sul, PR e } \\
\text { Arvorezinha, RS }\end{array}$ & C. fimbriata \\
\hline
\end{tabular}

De modo a permitir a identificação do patógeno Fusarium, causador de podridão-de-raízes, Poletto et al. (2012) determinaram as características morfológicas e moleculares de seis isolados de Fusarium spp. Os isolados foram obtidos de seis ervais nos municípios de Anta Gorda, Arvorezinha, Ilópolis e Putinga, no Rio Grande do Sul. Em cada erval foram arrancadas três árvores doentes, com coleta de amostras das raízes. Diferentemente dos demais artigos, os autores, além de utilizar o meio de cultura BDA, também utilizaram o meio FCA (folha de cravo e ágar). Entre os isolados analisados, foram identificadas as espécies $F$. oxysporum e $F$. solani. Ambas se mostraram patogênicas e com baixa variabilidade genética dentro da espécie.

Mezzomo et al. (2018a) avaliaram o efeito de diferentes meios de cultura e níveis de luminosidade no crescimento e esporulação de Fusarium spp. Os meios utilizados foram BDA, BSA, MEA e V8, com 3 níveis de 
luminosidade: 0,12 e $24 \mathrm{~h}$ de luz branca. O meio BDA consiste em batata, dextrose e ágar, e é o meio de cultura mais comum e frequente em todos os artigos estudados. O BSA é composto por batata, sacarose e ágar; o MEA é extrato de malte e ágar, e o V8 consiste em suco de vegetais com ágar. Os autores concluíram que os meios recomendados para o crescimento do patógeno em questão, foram MEA e V8, enquanto para avaliar a esporulação, foram indicados os meios MEA e BSA. Ainda, independente do meio de cultura, a luz continua produziu maior concentração de esporos/mL de Fusarium spp.

Mezzomo et al. (2018b) realizaram a caracterização morfofisiológica e a identificação molecular de isolados patogênicos de Fusarium spp. As amostras de raízes e as mudas foram obtidas de ervais localizados nos municípios de Anta Gorda, Arvorezinha, Putinga, llópolis e Machadinho, no Rio Grande do Sul. Foram caracterizados 39 isolados de Fusarium spp. mas apenas sete foram testados quanto à patogenicidade com a inoculação do patógeno no substrato de erva-mate. As variáveis utilizadas para a caracterização morfofisiológica foram eficientes para distinguir os isolados em sete grupos, especialmente o comprimento dos macroconídios e esporulação. Os autores identificaram sete isolados como patogênicos, e as espécies $F$. solani e $F$. oxysporum como as principais causadoras da podridão-de-raízes nos ervais do Rio Grande do Sul. Os resultados obtidos por Mezzomo et al. (2018b) foram semelhantes aos encontrados por Poletto et al. (2006) e Poletto et al. (2012), em que as espécies $F$. oxysporum. e $F$. solani foram as mais comuns em ervais sendo as principais causadoras da podridão-deraízes.

Brito et al. (2021) estudaram isolados de C. fimbriata obtidos de erva-mate, foram analisadas as caracteristícas morfofisiológica, crescimento micelial em diferentes e a esporulação em meio de cultura e temperaturas. Os 11 isolados utilizados foram obtidos da Coleção de Fungos e Oomicetos Florestais da Embrapa Florestas, a partir de plantas doentes dos municípios de São Mateus do Sul, no Paraná e Arvorezinha, no Rio Grande do Sul. Os meios de cultura utilizados foram BDA (batata-dextrose-ágar), CA (cenoura-ágar) e V8. Segundo os autores, o meio BDA e meio V8 apresentaram os maiores crescimentos miceliais. As temperaturas foram avaliadas na faixa entre 8 a $36^{\circ} \mathrm{C}$, variando de 4 em $4{ }^{\circ} \mathrm{C}$. A temperatura ótima de crescimento e esporulação dos isolados foram de 22,5 e $22,4^{\circ} \mathrm{C}$, respectivamente. $\mathrm{O}$ gênero presente em Brito et al (2021) não foi encontrado em nenhum outro artigo revisado neste trabalho, provavelmente por se tratar de um patógeno novo na erva-mate. De acordo com Santos et al. (2018), esta espécie teve o seu primeiro relato em 2018, com mortalidade superior à $5 \%$ dos ervais avaliados em São Mateus do Sul e Arvorezinha.

\section{Métodos de controle de doenças de erva-mate}

Após a análise dos artigos, 3 deles foram classificados como estudos de métodos de controle para fungos da erva-mate (Tabela 3).

Tabela 3. Artigo sobre métodos de controle em ervamate.

\begin{tabular}{cccc}
\hline Autor & Local & $\begin{array}{c}\text { Método de } \\
\text { controle }\end{array}$ & Doença \\
\hline $\begin{array}{c}\text { Gomes et al. } \\
\text { (2001) }\end{array}$ & $\begin{array}{c}\text { Colombo, } \\
\text { PR }\end{array}$ & Biológico & Pinta-preta \\
$\begin{array}{c}\text { Grigoletti Junior } \\
\text { \& Auer (2003) }\end{array}$ & $\begin{array}{c}\text { Colombo, } \\
\text { PR }\end{array}$ & Químico & Pinta-preta \\
$\begin{array}{c}\text { Poletto et al. } \\
\text { (2010a) }\end{array}$ & $\begin{array}{c}\text { Anta Gorda, } \\
\text { RS }\end{array}$ & Cultural & Podridão-de-raízes \\
\hline
\end{tabular}

Gomes et al. (2001) e Grigoletti Junior \& Auer (2003) avaliaram a utilização de métodos biológicos e químicos para o controle da pinta-preta causada por $C$. spathulatum e Poletto et al. (2010a) avaliaram métodos culturais para controle da doença podridão-de-raízes causada por espécies de Fusarium.

O método biológico utilizado por Gomes et al. (2001) consistiu na inoculação dos isolados de Trichoderma spp. e Bacillus subtilis em folhas destacadas e mudas de ervamate com sinais de pinta preta. Os microoganismos com potencial de biocontrole foram obtidos de diferentes procedências em amostras de folhas de erva-mate e do solo de cultivo. Os autores concluíram que os isolados de Bacillus foram mais eficientes que os de Trichoderma, e em alguns casos reduziu-se até $90 \%$ o número de lesões das mudas. Além disso, o uso de antagonistas se mostrou viável para o controle da doença em mudas.

Grigoletti Junior \& Auer (2003) também estudaram métodos de controle para a pinta-preta, porém com produtos químicos. Os autores indicaram que o controle de fungos em erva-mate era normalmente realizado com fungicidas, entretanto estes não possuíam registro nos órgãos competentes (AGROFIT, 2021).

Os ensaios de controle químico foram realizados in vitro e in vivo por Grigoletti Junior \& Auer (2003). Para o teste in vitro, foram utilizados os produtos com as seguintes concentrações: benomyl $(0,5 \mathrm{~g} / \mathrm{L})$, calda bordalesa $(2,5 \mathrm{~g} / \mathrm{L})$, calda sulfocálcica $(4,0 \mathrm{~g} / \mathrm{L})$, captan $(2,4$ $\mathrm{g} / \mathrm{l})$ e fosfito $(2,0 \mathrm{~g} / \mathrm{l})$. O ensaio consistiu em utilizar folhas destacadas de erva-mate imersas no produto químico que 
posteriormente foram inoculadas com C. spathulatum. Os testes in vivo foram realizados com pulverização dos fungicidas em mudas. Os produtos químicos e suas concentrações utilizadas foram: vinclozolin (0,15\%); benomyl $(0,05 \%)$, mancozeb $(0,28 \%)$, oxicloreto de cobre $(0,30 \%)$, enxofre $(0,40 \%)$ e captan $(0,20 \%)$. Grigoletti Junior \& Auer (2003) concluíram que em ambos os testes realizados, os princípios ativos benomyl e captan apresentaram os melhores resultados para o controle da pinta preta.

O controle cultural para a podridão-de-raízes causada por Fusarium spp. foi estudado por Poletto et al. (2010a). $O$ ensaio consistiu na inoculação de $F$. solani e $F$. oxysporum em mudas tratadas com diferentes doses de calcário e de NPK, acima e abaixo do recomendado para a erva-mate. Foi utilizado delineamento experimental inteiramente casualizado fatorial com avaliações semanais pelo período de 8 meses e ocorreu de forma visual para identificação dos sintomas na parte aérea das mudas ao final do experimento foi avaliado o sistema radicular das plantas. Poletto et al. (2010a) concluíram que a aplicação dos produtos avaliados contribuiu para a maior severidade dos sintomas da podridão-das-raízes causadas por Fusarium spp. Além disso, a menor manifestação da doença ocorreu com a aplicação de NPK com $50 \%$ da dose recomendada e sem calagem.

\section{CONCLUSÕES}

É importante o correto diagnostico do patógeno de modo a definir a melhor estratégia de controle. O fungo mais frequentemente relatado em erva-mate (Ilex paraguariensis) é Fusarium spp., com destaque para as espécies Fusarium oxysporum e Fusarium solani, que foi identificado em diferentes compartimentos da planta, nas sementes e no solo. Este fungo também é o responsável pela doença podridão-de-raízes, que atinge a cultura na região Sul do Brasil. Mais recentemente, um novo fungo foi identificado na erva-mate, Ceratocystis fimbriata, que precisa ser mais aprofundadamente estudado, nos próximos anos.

\section{AGRADECIMENTOS}

Os autores agradecem à Coordenação de Aperfeiçoamento de Pessoal de Nível Superior (CAPES) pelo apoio na forma de bolsa de pós-graduação e ao CNPq pela bolsa de produtividade do último autor.

\section{REFERÊNCIAS}

AGROFIT. Sistema de registro de agrotóxicos do Ministério da Agricultura. 2021. Disponível em: http://agrofit.agricultura. gov.br/agrofit_cons/principal_agrofit_cons

BORGES, L.R. et al. Diversidade de fungos filamentosos em solo de monocultivo de erva-mate, llex paraguariensis St. Hil. Revista Acadêmica Ciência Animal, v.9, n.2, p.185-194, 2011.

BRITO, N.M. et al. Morphophysiological characterization of Ceratocystis fimbriata isolates from yerba mate. Ciência Rural, v.51, n.3, e20200579, 2021.

DANIEL, O. Erva-mate: sistema de produção e processamento industrial. Dourados: UFGD; UEMS, 2009.

OLIVEIRA, E. et al. Qualidade sanitária de sementes de ervamate. Unoesc \& Ciência-ACET, v.6, n.2, p.231-238, 2015.

PAULA, S. et al. Incidência de fungos em solos cultivados com erva-mate no Alto Uruguai gaúcho. Summa Phytopathologica, v.47, p.10-16, 2017.

GOMES, N.S.B. et al. Seleção de antagonistas para o controle de Cylindrocladium spathulatum em erva-mate. Boletim de Pesquisa Florestal, n.43, p.123-138, 2001.

GRIGOLETTI JÚNIOR, A.; AUER, C.G. Efeito de fungicidas no controle da pinta-preta da erva-mate. Pesquisa Florestal Brasileira, v.46, p.91-96, 2003.

IBGE - INSTITUTO BRASILEIRO DE GEOGRAFIA E ESTATÍSTICA. Estatística Paraná. 2021. Disponível em: https://sidra.ibge.gov.br/tabela/5457\#resultado.

MEDRADO, M.J.S., VILCAHUAMAN, L.J.M. Cultivo da erva-mate. Importância socioeconômica e ambiental. 2.ed. Embrapa Florestas, 2014.

MEZZOMO, R. et al. Mycelial growth and sporulation of Fusarium spp. pathogenic to llex paraguariensis in different culture media and under exposure to different light levels. Scientia Agraria, v.19, n.1, p.14-19, 2018a.

MEZzOMO, R. et al. Morphological and molecular characterization of Fusarium spp. pathogenic to Ilex paraguariensis. Cerne, v.24, n.3, p.209-218, 2018b.

PAULA, S. et al. Doenças fúngicas em erva-mate. Fungal disease in "erva-mate". Scientific Electronic Archives, v.11, n.2, p.27-34, 2018.

PIMENTEL, I.C. et al. Fungos endofíticos em folhas de erva-mate (Ilex paraguariensis A. St.-Hil.). Floresta, v.36, n.1, p.123-128, 2006.

POLETTO, I. et al. Zoneamento e identificação de Fusarium spp. causadores de podridão de raízes em plantios de erva-mate (Ilex paraguariensis A. St.-Hil.) na região do vale do Taquarí, RS. Ciência Florestal, v.16, n.1, p.1-10, 2006.

POletto, I. et al. Primeira ocorrência de Pythium sp. e Rhizoctonia sp. causando podridão-de-raízes em ervais no Rio Grande do Sul. Ciência Florestal, v.17, n.1, p.65-69, 2007.

POLETTO, I. et al. Efeito da aplicação de NPK e calcário sobre a podridão-de-raízes em mudas de erva-mate. Floresta, v.40, n.3, p.1-15, 2010. 
POLETTO, I. et al. Influência da inoculação de Fusarium spp. e níveis de sombreamento no crescimento e desenvolvimento da erva-mate. Ciência Florestal, v.20, n.3, p.513-521, 2010.

POLETTO, I. et al. Caracterização e patogenicidade de isolados de Fusarium spp. causadores de podridão-de-raízes da ervamate. Floresta, v.42, n.1, p.95-104, 2012.

POLETTO, I.et al. Aspectos epidemiológicos da podridão-deraízes da erva-mate (llex paraguariensis). Ciência Florestal, v.25, n.2, p.281-291, 2015

SANTOS, A.F. et al. First report of yerba mate wilt caused by Ceratocystis fimbriata in Brazil. Plant Disease, v.102, n.11, p.2381, 2018. 